\title{
Spatial and temporal phosphorylation of a transcriptional activator regulates pole-specific gene expression in Caulobacter
}

\author{
James A. Wingrove, Erin K. Mangan, and James W. Gober ${ }^{1}$ \\ Department of Chemistry and Biochemistry, University of California, Los Angeles, Los Angeles, California 90024-1569 USA
}

Polar localization of proteins in the Caulobacter predivisional cell results in the formation of two distinct progeny cells, a motile swarmer cell and a sessile stalked cell. The transcription of several flagellar promoters is localized to the swarmer pole of the predivisional cell. We present evidence that the product of the flbD gene is the transcriptional activator of these promoters. We show that FlbD is distributed in all cell types and in both poles of the the predivisional cell. We also demonstrate that FlbD can be phosphorylated, and that a FlbD kinase activity is under cell cycle control. Cells expressing a FlbD mutant that should activate transcription in the absence of phosphorylation, exhibited an alteration in the temporal pattern of flagellin transcription. Furthermore, predivisional cells expressing the mutant FlbD failed to polarly localize flagellin synthesis. We propose that the phosphorylation of FlbD is restricted to the swarmer compartment of the predivisional cell, and serves as the control point for regulating the spatial transcription of flagellar promoters.

[Key Words: Caulobacter; phosphorylation; transcriptional activator; cell cycle; polarity]

Received June 25, 1993; revised version accepted August 3, 1993.

Polar localization of gene products is an integral aspect of cellular differentiation in Caulobacter. A programmed sequence of differentiation events occurs within each cell cycle, resulting in the formation of two distinct daughter cells, a motile swarmer cell, and a sessile stalked cell (for review, see Newton and Ohta 1990; Gober and Shapiro 1991; Gober et al. 1991a). These two cell types differ in morphology, the capacity to reinitiate DNA replication, and their program of gene expression. Asymmetry is established in the predivisional cell, resulting in the biogenesis of a polar flagellum at the incipient swarmer cell pole and the specific programming of the stalked cell chromosome to reinitiate DNA replication. The molecular mechanisms underlying the generation of asymmetry in Caulobacter are similar to those operating in organisms as diverse as Bacillus, Drosophila, and the nematode (for review, see Horvitz and Herskowitz 1992).

Spatial localization of proteins in the predivisional cell type dictates the developmental fate of the progeny cells. Two different mechanisms are responsible for polar protein localization in Caulobacter. First, proteins are often specifically segregated to progeny stalked or swarmer cells. For example, two heat shock proteins, DnaK and Lon, are targeted to the stalked cell pole of the predivi-

${ }^{1}$ Corresponding author. sional cell (Reuter and Shapiro 1987). Conversely, motility-related proteins, such as flagellar and chemotaxis proteins, are targeted to the swarmer pole of the predivisional cell (Nathan et al. 1986; Loewy et al. 1987; Alley et al. 1992). The methyl-accepting chemotaxis receptor McpA is specifically targeted to a discrete location at the pole of predivisional cells (Alley et al. 1992). The process that recruits McpA to the pole is not understood. It is likely, however, that a specialized structure is present at the swarmer pole that serves to direct the assembly of flagellar and chemotaxis gene products. The pole of the predivisional cell is derived from the previous cell division site, suggesting that asymmetry is an intrinsic property of the Caulobacter cell cycle. A second mechanism that serves to position gene products is polar gene expression. The gene encoding DNA gyrase-B subunit, an essential DNA replication protein, is expressed exclusively in the stalked pole of the predivisional cell $(\mathrm{M}$. Rizzo, L. Shapiro, and J. Gober, in prep.). Asymmetry in flagellar gene expression is achieved through the localization of flagellar mRNA (Milhausen and Agabian 1983; Gober et al. 1991b; Gober and Shapiro 1992). A consequence of mRNA localization is that the expression of a subset of flagellar genes is confined to the swarmer pole of the predivisional cell. Previously, we have investigated the mechanism of flagellar mRNA localization and found that all the information necessary for the polar localization of gene expression is contained within the 
promoter DNA sequence (Gober et al. 1991b). This experimental finding suggests that polar transcription is responsible for the localization of flagellar mRNA (Gober et al. 1991b; Gober and Shapiro 1992). Swarmer pole-specific transcription occurs in late predivisional cells after a constriction between the swarmer and stalked cell compartments has formed, but before separation of the progeny cells, and is limited to genes that encode external flagellar structures.

The promoters that exhibit polar transcription, the hook operon, flaNQ, and the 25-kD flagellin gene, flgK, share similar cis-regulatory sequences, suggesting that temporal and spatial transcription is accomplished through a common mechanism (Gober et al. 1991c; Gober and Shapiro 1992). All three promoters are expressed late in the cell cycle and are transcribed by $\sigma^{54}$. containing RNA polymerase (Mullin et al. 1987; Brun and Shapiro 1992). Expression of $\sigma^{54}$ promoters is achieved through the action of transcriptional activator proteins that bind to enhancer sequences commonly located $\sim 100$ bp from the transcription start site (for review, see Kustu et al. 1989/. Each of these flagellar promoters contains a conserved enhancer sequence known as an ftr element (Minnich and Newton 1987; Mullin et al. 1987; Mullin and Newton 1989; Gober et al. 1991c). The temporal and spatial transcription of these promoters is probably regulated by proteins that bind to the $f t r$ enhancer sequence. Two proteins are known to bind to the $f t r$ enhancer, a $95-\mathrm{kD}$ protein, $\mathrm{Rf}-1$, and a $55-\mathrm{kD}$ protein (Gober et al. 1991c; Gober and Shapiro 1992). Both binding activities are under cell cycle control and occur at maximal levels in the predivisional cell type (Gober et al. 1991b; Gober and Shapiro 1992). The ftr-containing promoters also contain a binding site for integration host factor (IHF) located between the enhancer and the promoter sequences (Gober and Shapiro 1990; Gober and Shapiro 1992). The IHF-binding site in both the hook and flaNQ promoters is required for maximal levels of transcription (Gober and Shapiro 1990, 1992). As is the case with the enhancer-binding proteins, IHF is expressed under cell cycle control (Gober and Shapiro 1992).

In this paper we investigate the mechanism of both temporal and spatial transcription of ftr-containing flagellar promoters. We provide both genetic and biochemical evidence that the product of the $f l b D$ gene is the transcriptional activator of this subset of flagellar promoters. To examine the regulation of FlbD expression, we fused the carboxyl terminus to a 7-amino-acid epitope. Immunoblots prepared from cell cycle extracts showed that FlbD is present in all cell types during the cell cycle and in both compartments of the predivisional cell.

If FlbD is responsible for the temporal and spatial expression of these flagellar genes, then its activity must be modulated in both a cell cycle and spatial manner. We demonstrate that a kinase activity present in Caulobacter cell extracts can catalyze the phosphorylation of pure FlbD and is expressed under cell cycle control, with maximal activity occurring in the predivisional cell stage. We constructed a mutant FlbD protein that should be able to activate transcription in the absence of kinase activity. We then constitutively expressed this protein and assayed the cell cycle expression of $f \lg K$ and swarmer pole-specific expression of flagellins. Predivisional cells expressing the mutant FlbD fail to polarly localize flagellin synthesis. These results are consistent with the view that the phosphorylation of FlbD serves as a control point for regulating the spatial transcription of flagellar promoters.

\section{Results \\ Genetic evidence for the role of $\mathrm{flbD}$ in transcriptional activation of $\mathrm{ftr}$-containing flagellar promoters}

To determine the mechanism of compartment-specific transcription of the hook ( $l b G)$, flaNQ, and flgK promoters, we set out to genetically identify the transcriptional activator that binds to the ftr enhancer element. One consequence of the flagellar regulatory hierarchy is that strains with mutations in many early flagellar structural genes (class I genes) do not transcribe ftr-containing promoters such as flbG and flaNQ (Newton et al. 1989; Xu et al. 1989|. Therefore, the phenotype of strains with mutations in class I structural genes is indistinguishable from that of strains having mutations in genes that encode trans-acting regulatory proteins. We have now measured the level of transcription of the two other known $f t r$-containing promoters, $f 1 g L(27-\mathrm{kD}$ flagellin) and $f l g K$ (25-kD flagellin) using promoter fusions to a promoterless $1 a c Z$ reporter gene. The $f l g L-l a c Z$ transcription fusion generates 8720 units of $\beta$-galactosidase in a strain that is wildtype for motility (NA1000) and was not expressed in any class I mutant strains (Table 1). This pattern of expression is identical to that obtained with flaNQ and flbG promoter fusions (Newton et al. 1989). In contrast, the $1 \mathrm{lgK}-1 a c Z$ fusion differs in its pattern of expression, in that it did not require most of the class I gene products for expression. This result indicates that flgK transcription, unlike other $f t r$ promoters, is not influenced by flagellar assembly cues. The $f l g K$ promoter was expressed in all of the class I mutant strains tested, with two notable exceptions. Strains with a Tn5 insertion in either rpoN or $f 1 b D$ did not express the $f l g K-l a c Z$

Table 1. Transcription of flagellin genes in class I mutants

\begin{tabular}{llcc}
\hline & & \multicolumn{2}{c}{$\beta$-Galactosidase activity } \\
\cline { 3 - 4 } Strain & Genotype & flgL-lacZ & flgK-lacZ \\
\hline NA1000 & syn-1000 & 8720 & 6000 \\
SC1131 & fliLM & 271 & 5682 \\
SC1132 & flbF & 160 & 5538 \\
SC1029 & podW & 178 & 4318 \\
SC1048 & flaH & 252 & 5952 \\
SC508 & fliQ & 230 & 6258 \\
SC1032 & flbD & 125 & 224 \\
SC1055 & rpoN & 138 & 158 \\
\hline
\end{tabular}

${ }^{a}$ Expressed as units (Miller 1972). 
fusion (Table 1). rpoN encodes the $\sigma^{54}$ subunit of RNA polymerase (Brun and Shapiro 1992) and is therefore essential for the transcription of these class II and III genes. Sequence analysis has demonstrated that $f 1 b D$ would encode a $52-\mathrm{kD}$ polypeptide that is homologous to the transcriptional activators of other $\sigma^{54}$ promoters (Ramakrishnan and Newton 1990). These data suggest that FlbD may encode the previously identified $55-\mathrm{kD}$ protein that binds to the ftr enhancer (Gober et al. 1991c) and may directly activate the transcription of $f l g K$ as well as other ftr-containing promoters.

\section{Purification and characterization of FlbD}

To determine whether FlbD is the transcriptional activator of genes containing the ftr enhancer element, we subcloned the $f 1 b D$ gene from a cosmid that complements motility in a strain containing a Tn 5 insertion in $f l b D$ (SC1032). Using site-directed mutagenesis, a BamHI restriction site was introduced immediately adjacent to the translation initiation ATG codon. A 1800bp BamHI-EcoRI DNA fragment from this construction, which contains the entire $f l b D$ coding sequence, was then subcloned into the expression vector pTrcHisA, so that a fusion protein was created between the leader sequence of the vector and the full-length FlbD protein. The amino terminus $(\sim 3-\mathrm{kD})$ of this fusion contains both a stretch of histidine residues and a peptide se- quence from bacteriophage $\mathrm{T} 7$ coat protein. The HisFlbD fusion protein was used in all in vitro experiments.

The fusion protein was purified as described in Materials and methods. The His-FlbD preparation eluted from a nickel-Sepharose column contained a predominant Coomassie blue-stained protein band with an apparent molecular mass of $54 \mathrm{kD}$ (Fig. 1A). A second lower molecular mass polypeptide $(\sim 42 \mathrm{kD})$ was often seen in these fractions. The abundance of this smaller protein increases upon storage of the preparation, suggesting that it is a product of the degradation of FlbD. The $54-\mathrm{kD}$ polypeptide is likely to be the His-FlbD fusion protein, as it reacted in an immunoblot with an antibody directed against the amino terminus of the fusion (Fig. 1B). To demonstrate that purified FlbD binds specifically to ftr promoters, two different gel mobility shift experiments were performed. In the first experiment, purified FlbD was incubated with ${ }^{32} \mathrm{P}$-end-labeled fragments containing promoter DNA from each of the four ftr-containing genes. In all four cases, a shift in the electrophoretic mobility of the promoter DNA was observed when incubated with highly purified FlbD fusion protein, indicating that FlbD binds to all of these promoters (Fig 1C). To determine whether binding required an intact ftr enhancer sequence, a gel mobility shift competition experiment was performed (Fig. 2). A radioactive, doublestranded oligonucleotide containing the ftr enhancer sequence from $f l b G$ was used to assay FlbD-binding

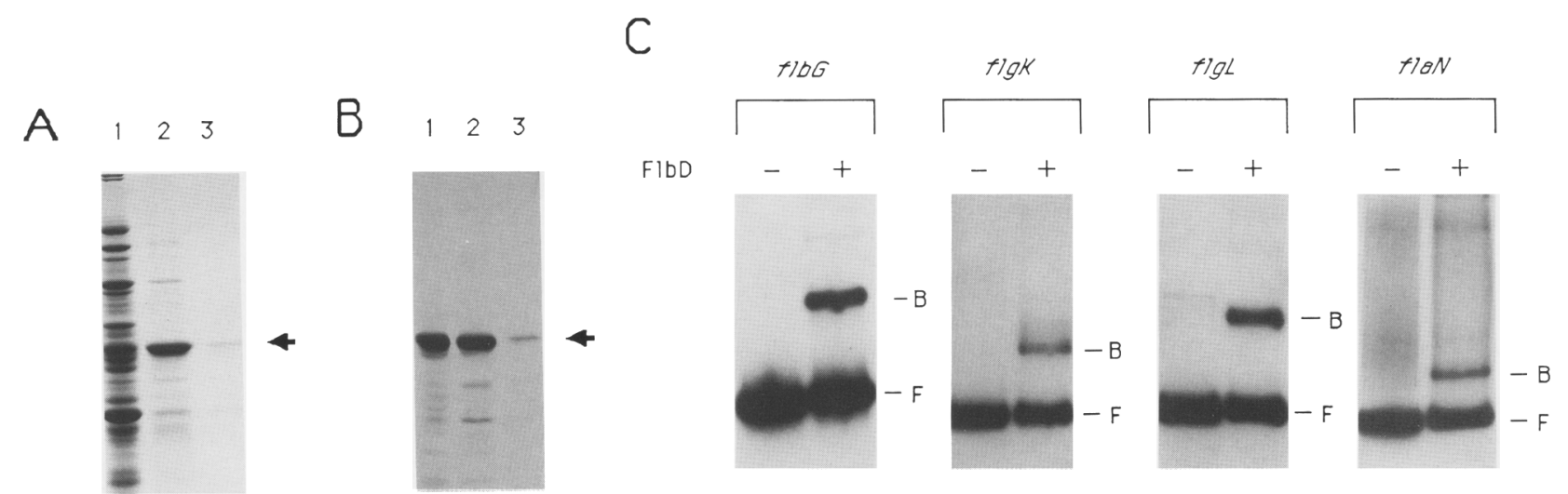

Figure 1. Purified FlbD binds to promoter DNA containing the ftr enhancer region. (A) SDS-PAGE of the purification of the His-FlbD fusion protein stained with Coomassie blue. The 1365 -bp $f l b D$-coding region was cloned in-frame into the vector $\mathrm{pTrcHisA}$, which allowed for the expression of the $52-\mathrm{kD}$ flbD product fused to a $3-\mathrm{kD}$ amino-terminal peptide containing a polyhistidine region. (Lane 1) Proteins present after IPTG-induced expression in E. coli; (lane 2) proteins present in inclusion bodies from the same IPTG-induced culture; (lane 3) elution of highly purified His-FlbD from nickel-Sepharose. $(B)$. Immunoblot of the same protein fractions of $A$ using antibody directed against the fusion portion of His-FlbD, and secondary antibody conjugated to alkaline phosphatase. (Lane 1) Crude extract from culture induced with IPTG; (lane 2) inclusion body fraction from culture induced with IPTG; (lane 3) highly purified fraction from the nickel-Sepharose column. $(C)$ Gel mobility shift analysis performed with $f$ tr-containing promoter fragments and highly purified His-FlbD. ${ }^{32}$ P-Endlabeled fragments containing the promotersequences of $f l b G, f l g K, f l g L$, and $f l a N$ (see Materials and methods) were incubated either with or without pure His-FlbD and were then electrophoresed in a nondenaturing, $8 \%$ polyacrylamide gel. $(B)$ DNA complexed with protein; (F) free DNA. (D). Comparison of the ftr sequences of $f l b G, f l g K, f l g L$, and flaNQ. The distance in base pairs relative to the transcription start site is indicated by the number located above each sequence. 


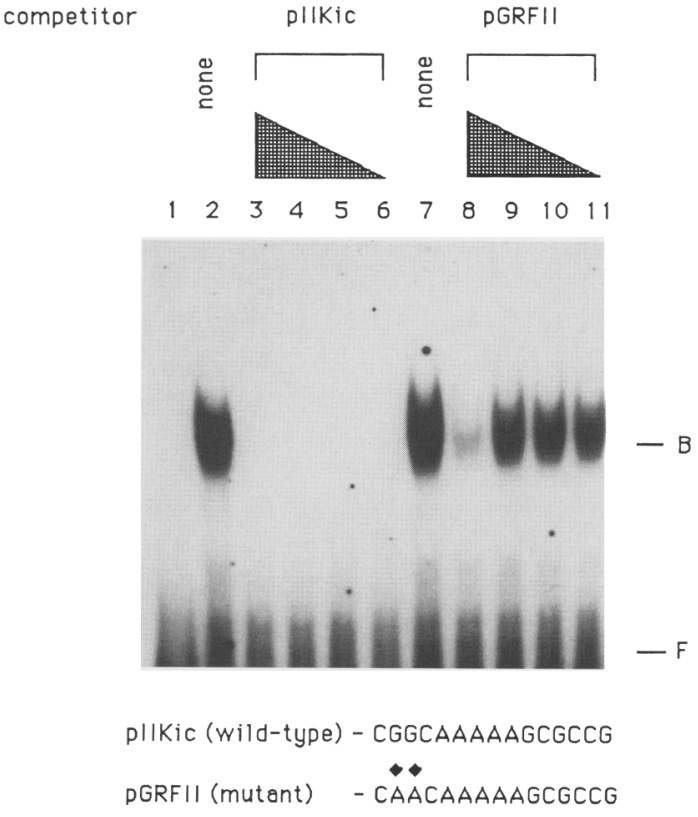

Figure 2. DNA binding competition assay to determine FlbDbinding specificity. ${ }^{32} \mathrm{P}$-Labeled double-stranded oligonucleotide representing the $f t r$ sequence of $f l b G(-80$ to $-120 \mathrm{bp}$ from the transcription start) (Gober et al. 1991a) was used as a binding substrate $(0.1 \mathrm{pmole} / \mathrm{lane})$. Increasing amounts of nonradioactive, competitor plasmid containing either the wild-type $f l b G$ promoter (PII-Kic) (Gober et al. 1991a) or a flbG promoter with a 2-bp mutation in the $f t r$ enhancer (pGRFII) (Gober and Shapiro 1992) were incubated with His-FlbD and the labeled oligonucleotide and electrophoresed on a nondenaturing, $8 \%$ polyacrylamide gel. All lanes contained labeled ftr oligonucleotide. (Lane 1) Labeled ftr oligonucleotide without protein; (lanes 2,7) pure His-FlbD, no competitor; (lane 3) protein plus 0.5 pmole of wild-type competing plasmid; (lane 4) protein plus 0.2 pmole of wild-type competing plasmid; (lane 5) protein plus 0.1 pmole of wild-type competing plasmid; (lane 6) protein plus 0.05 pmole of wild-type competing plasmid; (lanes 8-11) pure His-FlbD plus $0.5,0.2,0.1$, and 0.05 pmole, respectively, of mutant $f t r$ competitor, pGRFII. Sequences of wild-type $f l b G$ ftr (PII-Kic) and mutated flbG ftr (pGRFII) are shown below. activity. Plasmids containing either the wild-type $f l b G$ promoter or an $f l b G$ promoter that contained a 2-bp mutation in the $f t r$ enhancer were used as nonradioactive competitors (Fig. 2). This ftr mutation completely abolishes $f l b G$ transcription in vivo /Gober and Shapiro 1992). The wild-type $f 1 b G$ promoter effectively competed for DNA-binding activity at one-half the concentration of the labeled oligonucleotide probe. In contrast, a fivefold molar excess of the $f l b G$ promoter with the mutant $f t r$ competed only slightly for FlbD binding (Fig. 2). These experiments indicate that FlbD requires the same $f t r$ sequences for binding as are required for in vivo transcriptional activation of the $f l b G$ promoter. They also indicate that FlbD is likely to be the transcriptional activator of promoters with $f t r$ enhancers.

\section{Temporal regulation of flbD expression}

The timed transcriptional activation of ftr-containing promoters may be accomplished by modulating the cellular levels of FlbD during the Caulobacter cell division cycle. To test this model, a 7-amino-acid M2 epitope was fused to the carboxyl terminus of FlbD. A BamHI restriction site was introduced by site-directed mutagenesis directly after the final $f l b D$ codon (Fig. 3A). This construction results in the addition of 9 amino acids to the carboxyl terminus of FlbD. The modified $f 1 b D$ was then subcloned into plasmid pIM20, creating an in-frame fusion protein with the M2 epitope. The promoter that expresses $f l b D$, from the fliFflbD operon, was cloned 5' to this fusion, and the entire construction was mated into Caulobacter on a plasmid. To test whether the epitope-tagged FlbD could function properly, a complementation assay was performed (Fig. 3B). The FlbD::M2 fusion plasmid was introduced into a recombination deficient ( $\mathrm{rec}^{-}$), flbD::Tn5 mutant (SC1032), and motility was assayed by stabbing the cells into semisolid swarm agar. Motility is characterized by a large zone of growth that surrounds the point where the cells were inoculated. The FlbD::M2 fusion restored motility in the $f 1 b$ -

A
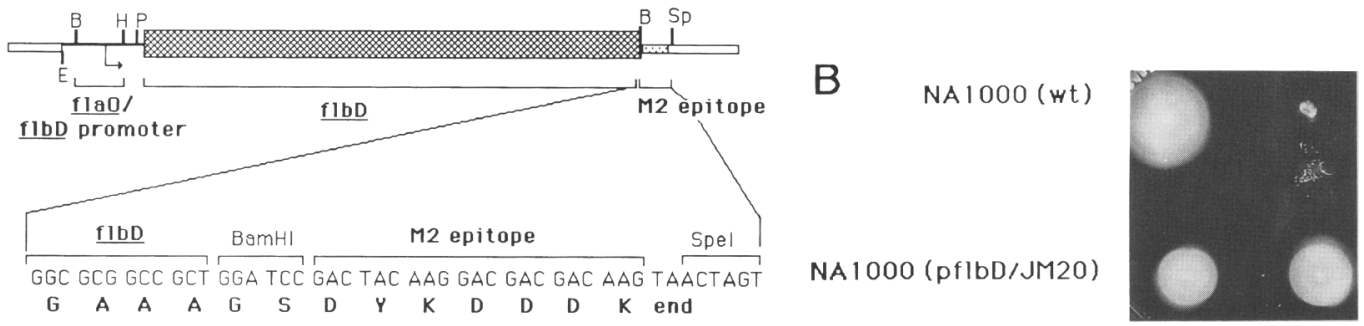

$\mathrm{SC} 1032(\mathrm{flbD})$

$\begin{array}{llllllllllllllllll}G & A & A & A & G & S & D & Y & K & D & D & D & K & \text { end }\end{array}$

Figure 3. Construction of a FlbD-epitope tag protein fusion. (A) Schematic map of the construction of a FlbD::M2 fusion. A BamHI restriction site was introduced following the final codon of $f I b D$ by site-directed mutagenesis. This was ligated to pIM20, creating an in-frame fusion of $f l b D$ with the 7-amino-acid M2 epitope. A 0.3-kb BamHI-HindIII fragment containing the fliFflbD operon promoter was then ligated $5^{\prime}$ to this fusion protein. The entire construction was then ligated into pRK290/20R for introduction into Caulobacter. (B) pFlbD/JM20 was introduced into recombination deficient $\left(\mathrm{rec}^{-}\right)$wild-type and flbD::Tn5 (SC1032) strains of Caulobacter, and motility was assayed in semisolid agar. Motility is indicated by a wide halo of bacterial growth surrounding the initial point of inoculation. 
$D:: \operatorname{Tn} 5$ mutant (Fig. 3B), indicating that the M2 peptide fused to the carboxyl terminus of FlbD does not significantly interfere with FlbD function.

Two different experiments were performed to assay the cell cycle expression of FlbD::M2. First, the cell cycle pattern of synthesis of FlbD was assayed by synchronizing cultures that harbored the FlbD::M2 fusion plasmid and pulse-labeling proteins with $\left[{ }^{35}\right.$ S $]$ methionine at different times during the cell cycle. Labeled FlbD::M2 was then immunoprecipitated from extracts using antiM2 antibody and subjected to polyacrylamide gel electrophoresis (PAGE). The synthesis of FlbD::M2 was under cell cycle control (Fig. 4A), with expression beginning in early stalked cells and peaking slightly in predivisional cells. This pattern is similar to the pattern of expression of mRNA transcribed from this promoter (Van Way et al. 1993). To determine whether the availability of FlbD was temporally controlled or restricted to the predivisional cell type, we performed an immunoblot on extracts prepared from synchronized cells harboring the FlbD::M2 fusion plasmid (Fig 4B). The level of FlbD::M2 varied slightly during the cell cycle but was present in all cell types, including those that do not express $\mathrm{ftr}$ promoters. The relatively constant level of FlbD::M2 throughout the cell cycle indicates that the rate of turnover of the protein probably increases at times when its rate of synthesis increases. The net result would be a relatively constant level of FlbD throughout the cell cycle. We should note that the epitope fusion at the amino terminus of FlbD may also alter its stability. The cell cycle pattern of FlbD::M2 synthesis did not parallel the temporal pattern of flagellin expression in this experiment (Fig. 4C). These data indicate that FlbD levels are not subject to cell cycle control and suggests that
FlbD activity may be modulated as a function of the cell cycle.

\section{Role of FlbD in regulating polar flagellar gene expression}

The polar transcription of $f t r$-containing promoters may result from the specific positioning of essential transcription factors to the swarmer pole of the predivisional cell. We performed two different experiments to determine whether FlbD is specifically targeted to the swarmer pole. The intracellular distribution of the FlbD::M2 fusion was first assayed by immunofluorescence microscopy (Fig. 5A). This technique has been employed successfully to examine the targeting of the methyl-accepting chemotaxis receptor to the poles of both Caulobacter and Escherichia coli (Maddock and Shapiro 1993; M. Alley, J. Maddock and L. Shapiro, unpubl.). This assay demonstrated that the FlbD::M2 fusion was present in both poles of the predivisional cell and was also present in all cell types (Fig. 5A). The latter result agrees with the cell cycle immunoblot experiment presented above (see Fig. 4B). A negative control for this experiment consisted of reacting anti-M2 antibody with cells that did not contain FlbD::M2. In this case, the cells did not fluoresce and were not visible (not shown). To confirm the results obtained by microscopy, we performed an immunoblot on newly divided progeny swarmer and stalked cells. In this experiment, a culture was synchronized and permitted to progress through the entire cell cycle. Immediately following cell division, the progeny swarmer and stalked cells were separated by centrifugation through Ludox LS, and extracts were prepared and subjected to an immunoblot following electro-

A ${ }^{35}$ S-Immunoprecipitation (anti-M2)

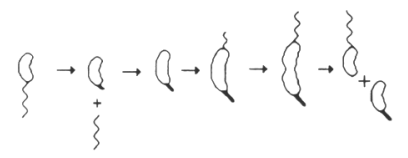

$\begin{array}{lllllll}\text { Cell division units } & 0 & 0.2 & 0.4 & 0.6 & 0.8 & 1.0\end{array}$

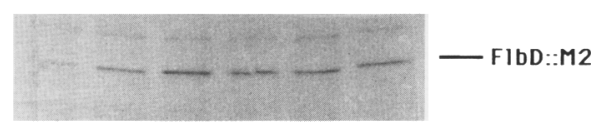

C ${ }^{35}$ S-Immunoprecipitation (anti-flagellin)

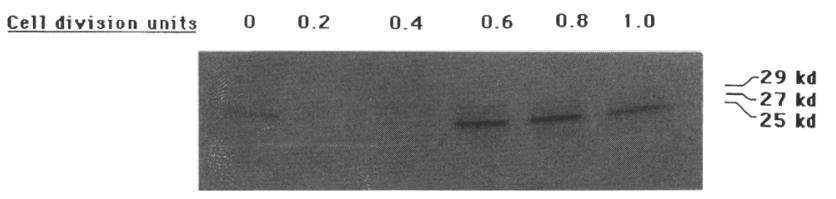

B Immunoblot

$\begin{array}{lllllll}\text { Cell division units } & 0 & 0.2 & 0.4 & 0.6 & 0.8 & 1.0\end{array}$

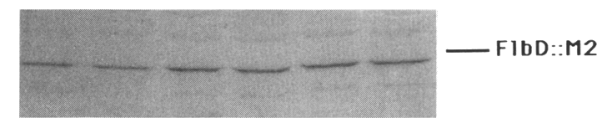

Figure 4. Cell cycle pattern of FlbD-M2 expression. $(A)$ Cell cycle synthesis of FlbD::M2. Swarmer cells were isolated, suspended in fresh medium, and allowed to progress through the cell cycle. Periodically, a sample was removed and proteins were labeled with Trans ${ }^{35} \mathrm{~S}$-label. Samples were labeled at $0,45,90,120$, 150 , and $180 \mathrm{~min}$. The cell types present at each time point, as assayed by microscopy are represented schematically above each lane. Extracts were prepared, and FlbD::M2 was immunoprecipitated using monoclonal anti-M2 antibody in conjunction with Staphylococcus aureus cells. Immunoprecipitated protein was subjected to PAGE and visualized on x-ray film following fluorography. (B) Assay of the level of FlbD::M2 throughout the cell cycle by immunoblot. Extracts from the above experiment were electrophoresed, transferred to nitrocellulose, and probed with monoclonal anti-M2 antibody. Antibody-antigen complexes were detected with secondary antibody conjugated to alkaline phosphatase. $(C)$ Cell cycle expression of flagellin protein. Flagellin was immunoprecipitated with anti-flagellin antibody using the ${ }^{35} \mathrm{~S}$-labeled cell extracts from $A$. 


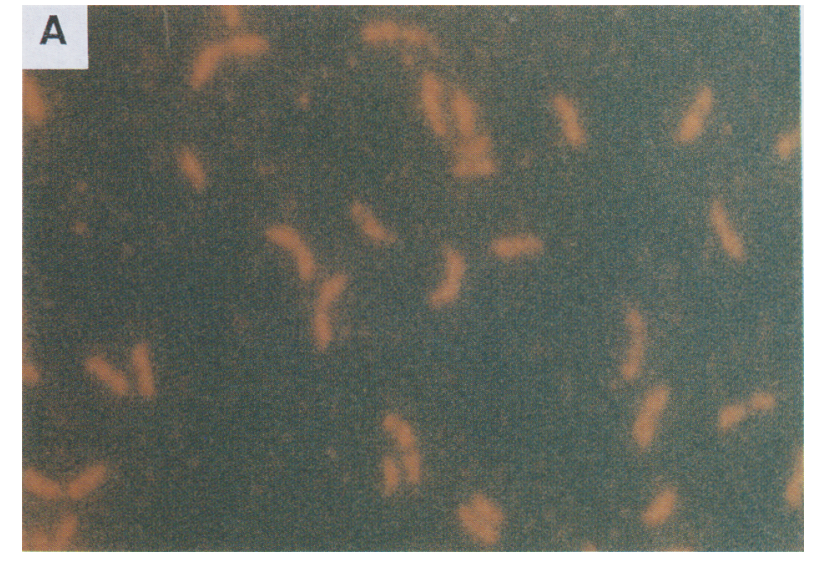

B
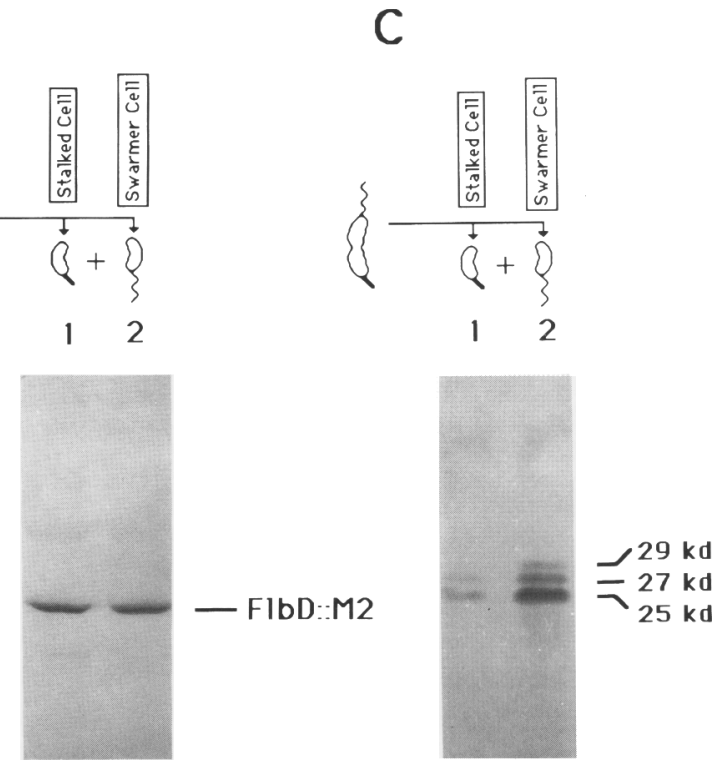

Figure 5. Localization of FlbD-M2 in the predvisional cell. $(A)$ Immunofluorescence microscopy with anti-M2 antibody. Immunofluorescence was performed on Caulobacter cells harboring $\mathrm{pFlbD} / \mathrm{JM} 20$ using monoclonal anti-M2 antibody. Secondary goat anti-mouse antibody was conjugated to biotin. The complex was detected by using Texas red conjugated to streptavidin. $(B)$ Cell type distribution of FlbD::M2 immediately following cell division. Cells harboring $\mathrm{pFlbD} / \mathrm{JM} 20$ were synchronized and allowed to divide. The progeny cell types were separated by centrifugation in Ludox. Equal quantities of protein from the stalked and swarmer cell fractions were electrophoresed, and an immunoblot was performed using monoclonal anti-M2 antibody. Secondary antibody was conjugated to alkaline phosphatase. $(C)$ Cell type distribution of flagellin protein immediately following cell division. Immunoblot using polyclonal anti-flagellin antibody was performed on the same extracts used in $B$.

phoresis. Progeny stalked and swarmer cells contained equal amounts of FlbD::M2 (Fig. 5B), indicating that the protein is not preferentially targeted to either pole of the predivisional cell. As a control, an immunoblot was performed on these same extracts using anti-flagellin antibody. More flagellin was present in the progeny swarmer cells than in the stalked cells (Fig. 5C). A small amount of flagellin was present in the stalked cell fraction. This is because this fraction was slightly contaminated with predivisional cells that express high levels of flagellin. Unlike FlbD, the flagellins are targeted to the swarmer pole of the predivisional cell where they are assembled into the flagellum structure. These data suggest that the pole-specific expression of ftr-containing promoters is not the result of polar localization of FlbD.

\section{Temporal control of FlbD activity by phosphorylation}

The experimental data presented above demonstrates that FlbD is not under temporal regulation, nor is the protein spatially localized to the swarmer pole of the predivisional cell. The amino terminus of FlbD is homologous to the amino-terminal domain of a large family of regulatory proteins that usually respond to environmental cues (Nixon et al. 1986; for review, see Parkinson and Kofoid 1992). NtrC is the best known $\sigma^{54}$ transcriptional activator in this family of regulatory proteins and is activated through the phosphorylation (Ninfa and $\mathrm{Ma}$ gasanik 1986; Keener and Kustu 1988; Weiss and Magasanik 1988) of an aspartate residue (D54) in its amino terminus (Sanders et al. 1992). The amino-terminal domain of FlbD possesses the analogous aspartate residue (D52) that is phosphorylated in NtrC. Given that FlbD levels are not temporally or spatially controlled, it is possible that the expression pattern of flagellar promoters is the result of a transient activation of FlbD by phosphorylation.

If FlbD activity is regulated by phosphorylation, the aspartate residue at position 52 could be essential for the activity of the protein. We changed this residue to an alanine by site-directed mutagenesis. The mutant $f 1 b D$ (D52A) was introduced into a flbD::Tn5 (SC1032) strain, and motility was assayed by light microscopy. The mutant D52A $f l b D$ was unable to complement motility in this strain (not shown), indicating that the D52 residue is important for FlbD function. We then tested whether FlbD was phosphorylated in Caulobacter. To accomplish this, strains harboring the plasmid expressing epitope-tagged FlbD ( $\mathrm{pFlbD} / \mathrm{JM} 20$ ) were labeled with either Trans ${ }^{35} \mathrm{~S}$-label or inorganic ${ }^{32} \mathrm{PO}_{4}$. Two different strains were labeled, a wild-type (NA1000) strain and the mutant $f l b D:: \operatorname{Tn} 5$ (SC1032). As a control, a wild-type strain that did not carry plasmid pFlbD/JM20 was also labeled. Extracts were prepared, and the FlbD::M2 fusion was immunoprecipitated using anti-M2 antibody. Immunoprecipitated proteins were then separated by PAGE. A 54-kD ${ }^{32}$ P-labeled protein could be immunoprecipitated only from cultures expressing the FlbD::M2 fusion. At least two other ${ }^{32} \mathrm{P}$-labeled polypeptides coimmunoprecipitated with FlbD::M2 (Fig. 6A), indicating that other phosphorylated proteins may interact with FlbD. These proteins also coimmunoprecipitated with FlbD::M2 in the cultures that were labeled with ${ }^{35} \mathrm{~S} .{ }^{32} \mathrm{P}$ Labeled proteins could not be immunoprecipitated from cells that did not contain pFlbD/JM20 (Fig. 6A). In addition, labeled protein could not be immunoprecipitated 


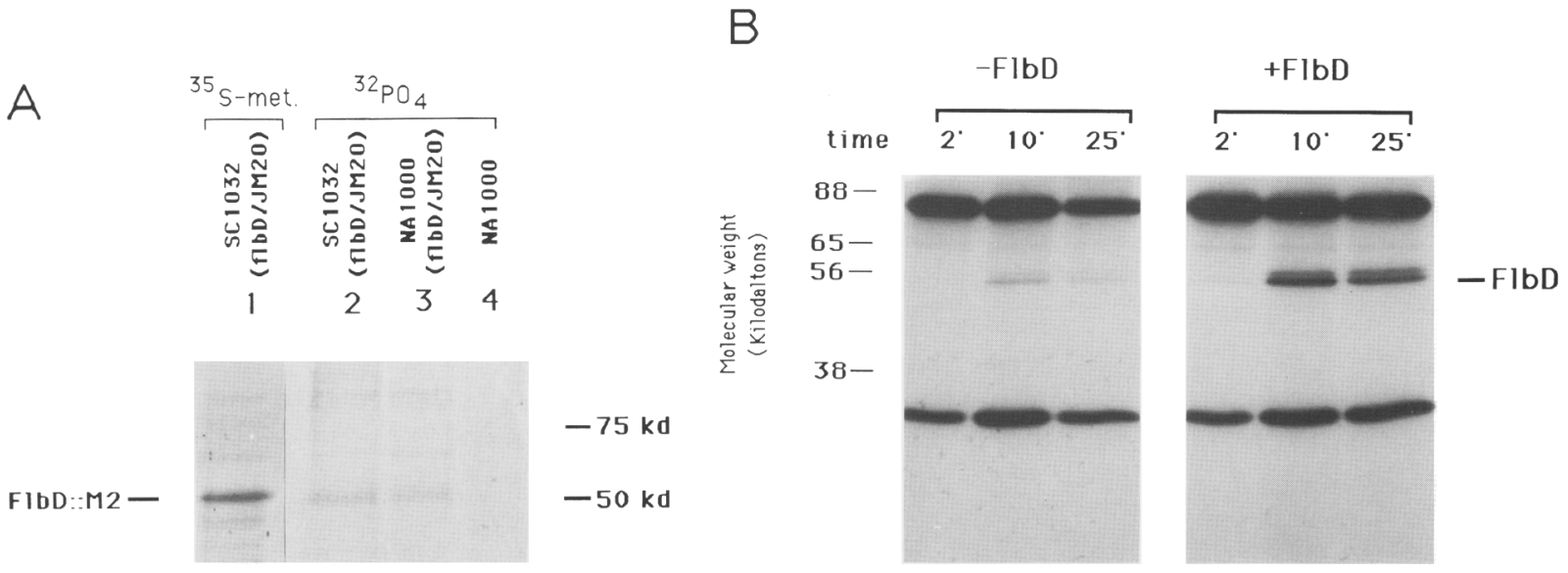

Figure 6. Phosphorylation of FlbD. (A) In vivo phosphorylation of FlbD::M2. NA1000 (wild type for motility) or SC1032 (flbD::Tn5) cultures harboring pFlbD/JM20 (or control cells without plasmid) were grown in low phosphate BM medium (Contreras et al. 1978). Cells were labeled with either Trans $-{ }^{35} \mathrm{~S}-1 \mathrm{abel}$ or ${ }^{32} \mathrm{PO}_{4}(200 \mu \mathrm{Ci} / \mathrm{ml})$ for $15 \mathrm{~min}$. FlbD-M2 was immunoprecipitated with monoclonal anti-M2 antibody as described previously, and the labeled proteins were separated by SDS-PAGE. (B). In vitro phosphorylation of FlbD. Approximately $5 \mu \mathrm{g}$ of crude cell extract from Caulobacter NA1000 was incubated at $30^{\circ} \mathrm{C}$ in the presence of $\left[\gamma^{-32} \mathrm{P}\right] \mathrm{ATP}$ either without $(-\mathrm{FlbD})$, or with $1 \mu \mathrm{g}$ of highly purified his-FlbD (+FlbD). Samples were removed at the time points indicated, passed through a Sepharose G-25 column to remove excess label, and frozen on dry ice. The samples were electrophoresed on a $12 \%$ SDS-polyacrylamide gel, and the gel was dried and exposed to film.

from ${ }^{32} \mathrm{PO}_{4}$ labeled cells that carried a methyl-accepting chemotaxis receptor (McpA) fused to the M2 epitope (not shown).

These experiments suggest that FlbD may be phosphorylated in vivo but do not rule out the possibility that the FlbD::M2 fusion protein is not phosphorylated; rather it coimmunoprecipitates with several phosphoproteins. We therefore tested whether cell extracts could catalyze the phosphorylation of pure FlbD in vitro (Fig. 6B). The reaction consisted of crude extract incubated in the presence of $\left[\gamma^{-32} \mathrm{P}\right] \mathrm{ATP}$ and, in some cases, $\sim 2.5 \mu \mathrm{g}$ of pure His-FlbD. Samples were removed after 5, 10, and $25 \mathrm{~min}$ of incubation. Because acyl-phosphates are inherently unstable, the reactions were quenched with EDTA, effectively chelating out $\mathrm{Mg}^{2+}$ ion, which is required for the dephosphorylation of this class of response regulators (Stock et al. 1992). Phosphorylation of 54-and 56-kD bands was seen in samples in which exogenous HisFlbD was added, with maximal phosphorylation occurring by $10 \mathrm{~min}$ (Fig. $6 \mathrm{~B}$ ). The presence of a double band might indicate that FlbD is post-translationally modified in addition to being phosphorylated. In the control reaction in which exogenous FlbD was absent, faint doublets were seen at 10 and $25 \mathrm{~min}$ (Fig. 6B). These bands were not seen when extracts were prepared from a $f l b D:: \operatorname{Tn} 5$ strain, suggesting that they may correspond to endogenous FlbD (not shown). A control reaction including His-FlbD and $\left[\gamma^{-32}\right.$ P]ATP, but lacking Caulobacter extract, yielded no labeled proteins corresponding to the molecular mass of FlbD (not shown).

The experiments described above employed cells or cell extracts from mixed, unsynchronized populations that contain all cell types. We therefore prepared cellcycle, stage-specific extracts from a synchronous culture of Caulobacter. These extracts were then used as a source of FlbD kinase in the in vitro phosphorylation assays. The phosphorylation of FlbD is under cell cycle control. Little or no activity was demonstrable in the early stages of the cell cycle (Fig. 7). The peak in phosphorylation activity occurred between 120 and $150 \mathrm{~min}$ into the cell cycle, corresponding to the time when the $f t r$-containing flagellar genes are maximally transcribed (Fig. 7). At $180 \mathrm{~min}$, after the cells had undergone division, phosphorylation activity was diminished (Fig. 7). This experiment supports the model that the cell cycle

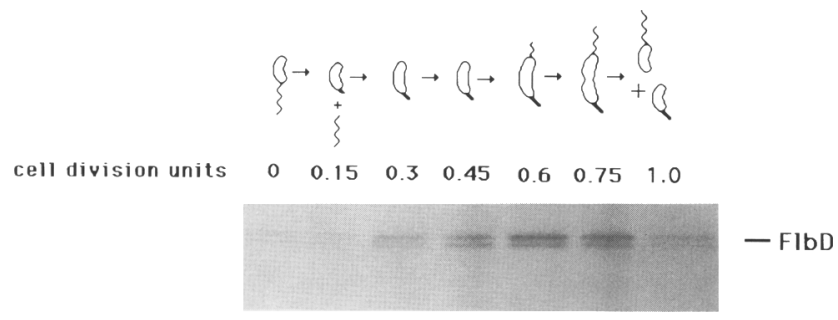

Figure 7. Cell cycle phosphorylation of FlbD. Swarmer cells isolated from wild-type strain NA1000 were allowed to proceed synchronously through the cell cycle. The generation time was $180 \mathrm{~min}$. Every $30 \mathrm{~min}$, samples were removed and lysed by sonication in the presence of protease inhibitors. Cell types at the time of sample removal are indicated above each time point. Protein concentrations were determined by Bradford assay. Equal amounts of protein from each of the stage-specific extracts was used in the phosphorylation assay, as described in Materials and methods. Samples were resolved on $12 \%$ SDSPAGE, and the phosphorylated proteins were visualized by autoradiography. The band corresponding to phosphorylated FlbD is indicated at right. 
phosphorylation of FlbD regulates the temporal transcription of flagellar genes.

\section{FlbD phosphorylation and the temporal regulation flagellar gene expression}

To assess the contribution of FlbD phosphorylation in regulating temporal transcription, we created a mutant protein that should be active in the absence of phosphorylation. This was achieved by changing a serine in the conserved central domain (S140) to a phenylalanine. A mutation of this type in $\mathrm{NtrC}$ (S160F) has been shown to activate transcription in vitro, in the absence of its cognate kinase NtrB (Popham et al. 1989; Weiss et al. 1991). The mutant NtrC, however, still responds to phosphorylation. We placed wild-type and the mutant (S140F) $f l b D$ under control of a $t a c$ promoter (which is expressed constitutively in Caulobacter) and assayed the cell cycle pattern of expression of both a flgK::1acZ fusion protein and a flgK-promoterless neo transcription fusion by immunoprecipitation. Cells overexpressing wild-type FlbD exhibited a normal pattern of flgK expression (Fig. 8A,C; see Fig. 7 for comparison with flagellin protein expression). Expression of both fusions was maximal in late predivisional cells. Note that expression in swarmer cells is characteristic of $f \operatorname{lgK}$ and is not the result of new transcription; rather, it is the result of translation of mRNA that was transcribed previously in the swarmer pole of predivisional cells (Milhausen and Agabian 1983; Gober et al. 1991c). In cells overexpressing the mutant FlbD (S140F), a slight increase in $f l g K$ expression in swarmer cells and stalked cells was observed between 0.15 and 0.45 division units (Fig. 8B and D, respectively). The peak in expression occurred at the same time as cells expressing wild-type FlbD, which is expected because the S140F mutant probably can respond to phos-

\section{A tac-flbD (wild type)}

Figure 8. Role of FlbD activation in regulating cell cycle expression of a flagellin promoter. $(A)$ Cell cycle pattern of $f l g K:: \operatorname{lacZ}$ protein fusion expression in a strain harboring wild-type $f 1 b D$ on an overexpression vector. Cells were synchronized as described in Materials and methods. Swarmer cells were suspended in fresh M2-glucose medium and allowed to progress through the cell division cycle at $32^{\circ} \mathrm{C}$. Samples were removed at $0,30,60,90,120,150$, and $180 \mathrm{~min}$, labeled with Trans ${ }^{35} \mathrm{~S}$-[label, and the FlgK:: $\beta$-galactosidase fusion was immunoprecipitated with anti- $\beta$-galactosidase antibody. For all time points, $1 \times 10^{6} \mathrm{cpm}$ of labeled protein was incubated with antibody. Immunoprecipitated protein was subjected to PAGE. The cell types present at each time point are represented schematically above each lane. (B) Cell cycle pattern of flgK::lacZ expression in a strain harboring mutant $f 1 b D$ S140F on an overexpression vector. Samples were treated as described in $A$. For all time points, $1 \times 10^{6} \mathrm{cpm}$ of labeled protein was incubated with antibody. $(C)$ Cell cycle pattern of neomycin phosphotransferase (NPTII) expression from a flgK-neo transcription fusion in a strain harboring wild type $f 1 b D$ on an overexpression vector. The experiment was performed exactly as described above, except the cells harbored a flgKneo transcription fusion on plasmid pRK290. The product of the neo gene, NPTII, was immunoprecipitated with anti-NPTII antibody $\left(5^{\prime}-3^{\prime}\right.$, Inc., Boulder, COl. For all time points, $1 \times 10^{6} \mathrm{cpm}$ of labeled protein was incubated with antibody. $(D)$ Cell cycle pattern of neomycin phosphotransferase (NPTII) expression from a $f l g K-$ neo transcription fusion in a strain harboring mutant $f l b D$ S140F on an overexpression vector. Samples were treated as described above. NPTII was immunoprecipitated using anti-NPTII antibody. For all time points, $1 \times 10^{6} \mathrm{cpm}$ of labeled protein was incubated with antibody.

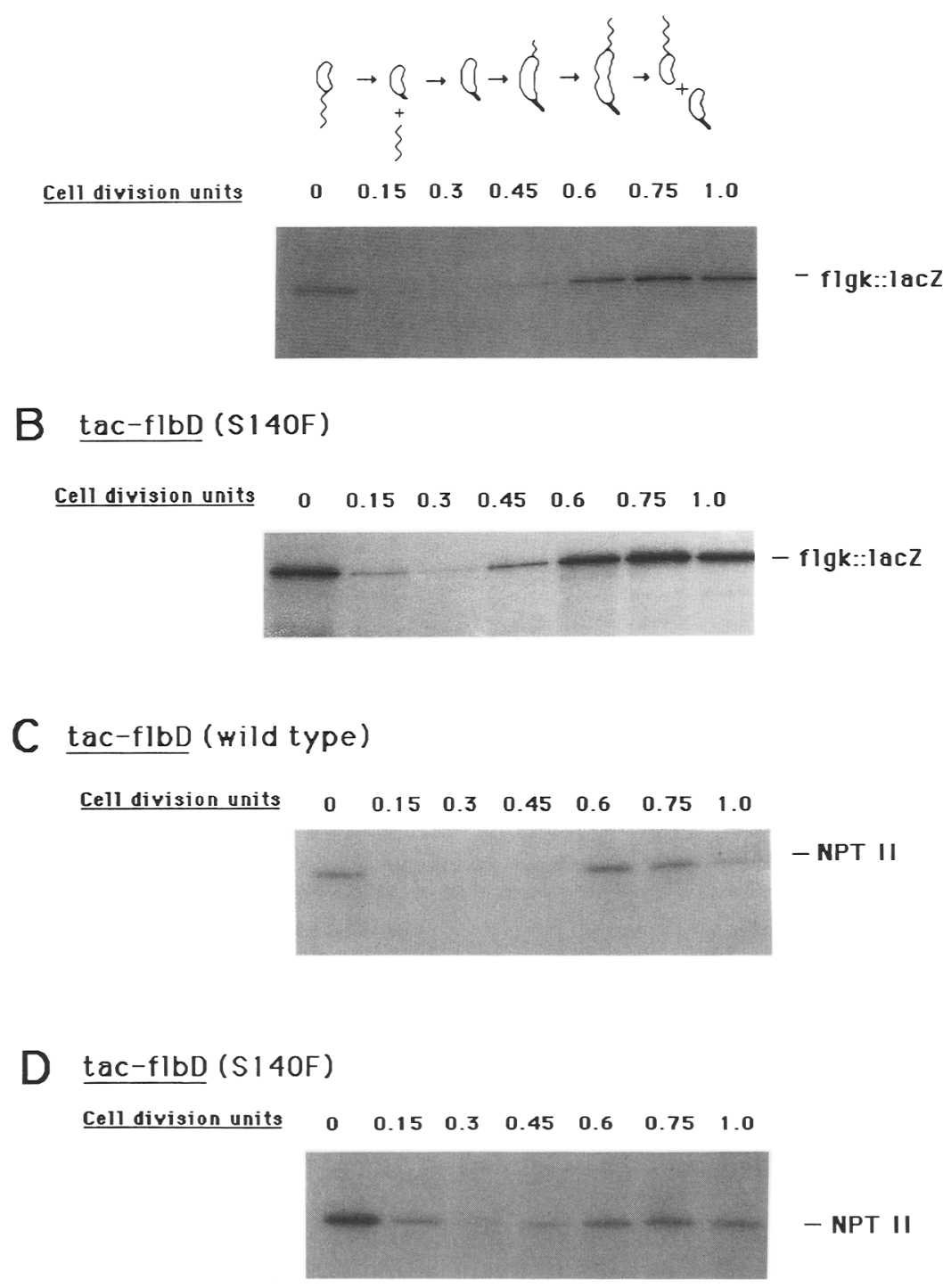


phorylation. The temporal pattern of expression in cells harboring the S140F mutant indicates that other factors in addition to the temporal phosphorylation of FlbD may have a role in regulating the cell cycle transcription of these promoters.

\section{Role of FlbD phosphorylation in regulating the spatial pattern of flagellar gene expression}

The mutant S140F FlbD was also used to determine the role of FlbD activation in swarmer pole-specific expression of flagellar genes. This experiment was essentially the same as that used previously to demonstrate swarmer pole-specific transcription (Gober et al. 1991; Gober and Shapiro 1992). Cells that overexpressed wildtype FlbD were synchronized and allowed to progress to the predivisional stage. Protein was pulse-labeled with Trans ${ }^{35} \mathrm{~S}$-label, the label was chased, and the cells were permitted to divide. Stalked and swarmer progeny were separated by centrifugation in Ludox, and flagellin was immunoprecipitated. The presence of labeled flagellin in progeny cell fractions provides a record of the polar location of flagellin expression in the predivisional cell. When cells overexpressed wild-type FlbD, labeled flagellin was present only in progeny swarmer cells (Fig. 9A). This result is a consequence of localized expression of this protein in the swarmer pole of the predivisional cell, as well as specific targeting to the assembling flagellum. The same experiment was performed on cells harboring a plasmid that overexpresses the mutant FlbD (S140F) (Fig. 9B). In addition to synthesizing the $25-\mathrm{kD}$ flagellin, these cells also reproducibly synthesized both the 29 and $27-\mathrm{kD}$ flagellin at this stage in the cell cycle. In wild-type cells, synthesis of these two minor flagellins usually ceases before the late predivisional stage. Therefore, the mutant FlbD (S140F) apparently affects the cell cycle timing of these two flagellins. Two unknown polypeptides that cross-react with the anti-flagellin antibody were also produced in this strain. These may be either flagellin degradation products or, in the case of the higher molecular mass band, may be post-translationally modified flagellin. Most notably, cells expressing the mutant FlbD (S140F) no longer exhibited swarmer cell compartment-specific flagellin expression. Labeled flagellin was present in both progeny swarmer and stalked cells. These data suggest that the modulation of FlbD activity has an essential role in polar gene expression and that the phosphorylation of FlbD is probably restricted to the swarmer pole of the predivisional cell.

\section{Discussion}

In this paper we investigate the mechanism of swarmer pole-specific transcription of a subset of flagellar genes in Caulobacter. Both genetic evidence and in vitro DNAbinding experiments presented here indicate that the product of the $f l b D$ gene is the transcriptional activator of this set of promoters. Although the gene encoding FlbD is expressed under cell cycle control, the levels of FlbD do not change significantly during the Caulobacter

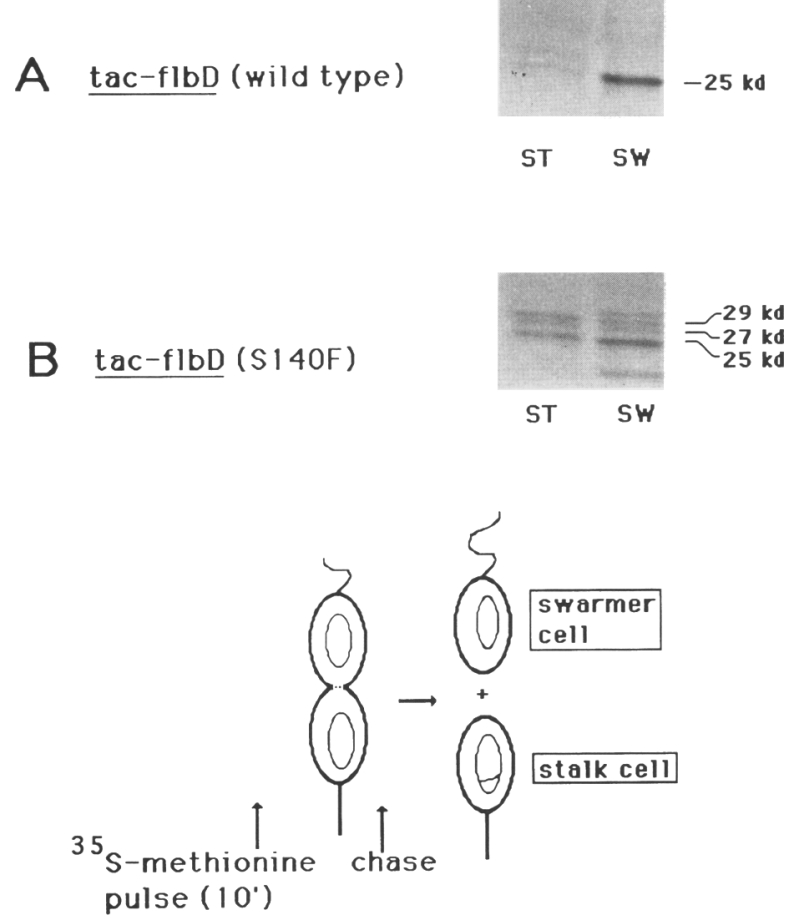

Figure 9. Role of FlbD activation in swarmer pole-specific expression and targeting of flagellins. $(A)$. Cells that overexpressed wild-type FlbD were synchronized and allowed to progress to the predivisional stage. Protein was pulse-labeled with $\left[{ }^{35} \mathrm{~S}\right] \mathrm{me}$ thionine, the label was chased, and the cells were permitted to divide. Stalked and swarmer progeny were separated by centrifugation in Ludox, and flagellin was immunoprecipitated with anti-flagellin antibody. Labeled $25-\mathrm{kD}$ flagellin is indicated. The presence of labeled flagellin in progeny cell fractions records the polar location of flagellin synthesis in the predivisional cell. $(B)$ The same experiment as described in $A$ was performed on cells harboring a plasmid that overexpresses the constitutive mutant FlbD (S140F). ${ }^{35}$ S-Labeled 25-, 27.5-, and 29-kD flagellins are indicated.

cell cycle. Overexpression of wild-type FlbD does not alter the temporal expression pattern of its target promoters. In addition, FlbD is not localized to the swarmer pole of the predivisional cell. We conclude that the activity of FlbD must be modulated in response to both temporal and spatial cues. A schematic depiction of the temporal and spatial activation of FlbD is shown in Figure 10. Although we presume that FlbD activity is modulated by phosphorylation, we acknowledge that this may not be the only influence on FlbD activity or on the expression of these flagellar genes. As depicted, FlbD is probably first activated in the early predivisional cell before a barrier has formed between the swarmer and stalked cell compartments. We hypothesize that the putative FlbD kinase responds to a morphogenetic cue such as a landmark in cell division or, perhaps, an early event in flagellar biogenesis. We propose that after the cell division constriction physically separates the swarmer and stalked cell compartments, FlbD becomes inactive in the stalked cell pole of the predivisional cell. This conclu- 
Figure 10. Model for the role of FlbD in regulating temporal and spatial gene expression in Caulobacter. A schematic depiction of the temporal and spatial activation of FlbD is shown. FlbD is represented by $\mathrm{D}$. Activated FlbD is represented by a filled-in D. FlbD is present in all cell types throughout the cell cycle and present in both poles of the predivisional cell. Therefore, the activity of FlbD must be modulated to activate temporal and spatial transcription. Phosphorylation of FlbD first occurs in early stalked cells. This may be attributable to the temporal synthesis of a FlbD kinase or, alternatively, kinase activity may be influenced by a morphogenetic cue. The phosphorylation of FlbD results in the timed transcription of flagellar promoters with $f t r$ enhancers. After a barrier forms between the two poles, active FlbD is restricted to the swarmer compartment of the predivisional cell. Inactivation of FlbD in the stalked cell pole may be the result of specific targeting of the FlbD kinase to the swarmer pole of the predivisional cell. Alternatively, separation of the swarmer and stalked poles may simply segregate the FlbD kinase in the stalk pole from its morphogenetic stimulus. We hypothesize that segregation of FlbD in the stalked cell pole, from its kinase, results in the the spontaneous dephosphorylation of FlbD. After cell division, FlbD returns to a nonphosphorylated form in the progeny swarmer cells.

sion is based on the experimental finding that the strain possessing an FlbD S140F mutant, which should be active in the absence of phosphorylation, no longer exhibits compartment-specific expression of flagellins. Dephosphorylation of FlbD in the stalked cell compartment is not likely to require a specific phosphatase because acyl phosphates of the type presumably present in FlbD hydrolyze spontaneously at a rapid rate. For example, the half-life of phospho-NtrC has been estimated at 3.6-5.0 min (Keener and Kustu 1988). Therefore, inactivation of FlbD in the stalked pole may simply be a consequence of sequestering the FlbD kinase in the swarmer cell compartment. Alternatively, the formation of a barrier between the two cell poles may separate the FlbD kinase in the stalked pole from its morphogenetic stimulus. During Bacillus sporulation, the formation of the septum is one of the earliest events that leads to the establishment of differing programs of gene expression in the developing mother and forespore compartments. Gene expression in one compartment is coupled to developmental events in the other compartment (for review, see Losick and Stragier 1992). In Caulobacter, we have no evidence that a coupling of gene expression between the swarmer and stalked cell compartments exists. In this case, the barrier formed between the stalked and swarmer cell compartments simply results in separating FlbD in the stalked cell cytoplasm from swarmer pole-specific activation cues.

The experiments using the FlbD S140F mutant demonstrate a critical role for phosphorylation in establishing a polar pattern of transcription. Strains expressing this mutant FlbD still exhibit cell cycle expression of $f l g K$, indicating that phosphorylation of FlbD is not the only regulatory event controlling cell cycle transcription. It is probable that other factors contribute significantly to the temporal pattern of flagellar transcription. $\mathrm{Rf}-1$, a $95-\mathrm{kD}$ protein that binds to the $\mathrm{ftr}$ enhancer, has been isolated (Gober and Shaprio 1992; Gober et al. 1991c). This cell cycle-controlled binding activity may have a role in regulating transcription of these promoters either by acting independently or through interaction with FlbD. Defining the role of $\mathrm{Rf}-1$ in temporal regulation awaits the isolation of the gene that encodes this protein. These promoters also require IHF and the $\sigma^{54}$ subunit of polymerase for transcription /Gober and Shapiro 1990; Gober and Shapiro 1992; Brun and Shapiro 1992). Both of these trans-acting factors are expressed under cell cycle control. Low levels of one or both of these factors in early stalked cells may be responsible for the decreased level of $f l g K$ transcription exhibited early in the cell cycle in cells that express the S140F mutant.

In contrast to other members of the response regulator family of transcription factors, FlbD is not phosphorylated in response to an environmental or nutritional cue but, rather, in response to a cell cycle-related event. This strategy is utilized in eukaryotic cells in which the phosphorylation of Oct-1, the transcription factor involved in the cell cycle transcription of histone $\mathrm{H} 2 \mathrm{~B}$ genes, is coupled to mitosis (Roberts et al. 1991). The coupling of FlbD activation to cell cycle events is presumably necessary for successful flagellar biogenesis. What is the nature of the kinase and cell cycle event that results in 
FlbD phosphorylation? The simplest mechanism to account for the temporally controlled phosphorylation of FlbD is that the synthesis of the putative FlbD kinase is regulated in a cell cycle fashion. This model would require that the kinase be degraded periodically during the cell division cycle. There is precedence for the timed degradation of proteins within the Caulobacter cell cycle. The methyl-accepting chemotaxis receptor McpA is proteolyzed when swarmer cells differentiate into stalked cells (Alley et al. 1993). The timing of this particular protease activity cannot account for the pattern of FlbD expression, but it is possible that other proteases are under temporal control. In an alternative model, the kinase may be present throughout the cell cycle and be active only during specific temporal periods. By analogy to other two-component regulatory systems, the FlbD kinase could be phosphorylated in response to a specific cell cycle cue such as an early polar structure or a cell division event. A similar model has been hypothesized to control cell division events in Caulobacter. Two different histidine kinases, pleC and divI, have been implicated in regulating cell cycle events in Caulobacter (Ohta et al. 1992; Wang et al. 1993). Mutations in pleC result in cells that are deficient in the biogenesis of polar structures such as the stalk and phage receptors (Sommer and Newton 1991; Wang et al. 1993). Cells with mutations in $\operatorname{divl}$, a suppressor of pleC, exhibit abnormal cell division (Sommer and Newton 1991). Therefore, it has been suggested that these kinases are components of a regulatory system that couples cell cycle events to polar morphogenesis (Ohta et al. 1992; Wang et al. 1993). These kinases probably do not encode the putative FlbD kinase, as strains with mutations in either of these genes still synthesize a flagellum (Sommer and Newton 1991), indicating that the genes encoding components of the flagellum are expressed in these mutants. Interestingly, the flagellum in pleC mutants does not function properly. It will be of interest to determine whether PleC and DivJ kinase activities are regulated in the same temporal fashion as the FlbD kinase.

Localization of phosphorylated FlbD to the swarmer cell compartment of the predivisonal cell may result from specific targeting of kinase activity to the swarmer pole. Polar protein localization in Caulobacter has been documented for components of the flagellum and chemotaxis machinery. The chemotaxis receptor McpA is localized to a specific polar region of the cytoplasmic membrane adjacent to the flagellum (Alley et al. 1992). There is a distinct possibility that the putative FlbD kinase is a membrane protein and, like McpA, is targeted to the swarmer pole of the predivisional cell. Many histidine kinases in the family of two-component regulatory systems are membrane proteins (Parkinson and Kofoid 1992).

Another plausible model is that the FlbD kinase senses the establishment of the polar organizing center that directs the localization of McpA and other proteins to the swarmer pole. This polar organizing center is probably established in the stalked cell shortly after the initiation of DNA replication. The establishment of polar- ity in the early stalked cell in Caulobacter is analogous to events that occur during the development of other organisms. For example, during the establishment of the terminal region in the early Drosophila embryo, a ligand of maternal origin is deposited at the termini of the egg (for review, see St. Johnston and Nüsslein-Volhard 1992). The presence of this ligand is sensed by a membrane protein, the product of the torso gene, which then transmits a signal to the inside of the egg. The torso gene product has homology to transmembrane receptor tyrosine kinases (Sprenger et al. 1989) and presumably represents the first member of a signal transduction pathway that senses the polar localization of the maternally derived ligand. The signal transmitted through this pathway eventually results in the transcription of terminal genes, such as tailless and hückebein (Klinger et al. 1988; Strecker et al. 1988; Weigel et al. 1990). As outlined above, a signal transduction pathway may also be operating to establish polar gene expression in Caulobacter, with the phosphorylation of FlbD being the final step in the signaling pathway. As is the case with Drosophila, the initial event in the establishment of polarity lies embedded within the architecture of the cell itself. In Caulobacter, the new pole is always opposite the stalk and is derived from the septum of the previous division. Therefore, the establishment of polarity is obligately coupled to cell morphogenesis.

\section{Materials and methods}

Bacterial strains, plasmids, and growth conditions

Synchronizable Caulobacter crescentus strain NA1000 was used as a motile, wild-type strain. SC1032 is a $f l b D:: \operatorname{Tn} 5 \mathrm{mu}$ tant strain (Ely and Ely 1989). Caulobacter cells were grown at $32^{\circ} \mathrm{C}$ in either PYE medium (Poindexter 1964) or minimal M2glucose medium (Johnson and Ely 1977). For ${ }^{32} \mathrm{PO}_{4}$-labeling experiments, cells were grown in low phosphate BM medium supplemented with glucose (Contreras et al. 1978). Promoterless lacZ transcription fusions were constructed using plasmid placZ/290 (Gober and Shapiro 1992; J. Gober and M.R.K. Alley, unpubl.). A flgK-lacZ transcription fusion was constructed by ligating a 580-bp PstI-EcoRI fragment containing the flgK promoter to placZ/290 (containing DNA sequences from -411 to +169 bp from the transcription start site). The flgL-lacZ transcription fusion was constructed by subcloning a 750-bp EcoRIHindIII fragment containing the flgL promoter into pllacZ/290 $(-650$ to +110 bp from the transcription start site). A flgK-lacZ fusion protein was constructed by ligating the 580 -bp PstIEcoRI flgK DNA fragment to pJBZ282 (Alley et al. 1993), creating an in-frame fusion of amino acid 28 of $f l g K$ to amino acid 8 of lacZ. flgK-neo contains a flgK transcription fusion of the 580-bp PstI-EcoRI promoter DNA fragment to a promoterless neo gene from Tn5 on plasmid pRK290/20R (Gober et al. 1991c). For overexpression of FlbD in Caulobacter, pRK290/ 20R plasmid containing an E. coli tac promoter was used (J. Gober, unpubl.).

\section{Cloning of flbD and construction protein fusions}

A cosmid (T13) was isolated that complemented motility in strain SC1032 (flbD::Tn5). A complementing 7.0-kb BamHI fragment was subcloned from T13. Finally, an $\sim 2.0-\mathrm{kb}$ PstI- 
$E c o$ RI fragment containing the entire $f l b D$-coding sequence was isolated. To construct a fusion protein for overproduction of FlbD in E. coli, a BamHI restriction site was introduced directly adjacent to the translation initiation codon. The 1800-bp BamHI-EcoRI fragment was then subcloned into pTrcHisA (Invitrogen, San Diego, CA) creating an in-frame fusion protein with the amino terminus of FlbD fused to the poly histidinecontaining leader peptide of pTrcHisA. To construct a fusion with the M2 epitope, a BamHI restriction site was introduced directly adjacent to the final codon of $f 1 b D$. A 1700-bp PstI$B a m H I$ fragment containing the entire $f 1 b D$-coding region was subcloned into plasmid pIM20 (Alley et al. 1993), creating an in-frame fusion protein with the M2 epitope (Fig. 3A). A 280-bp $B a m H I-H i n d I I I$ fragment containing the promoter for the fliF$f l b D$ operon was ligated $5^{\prime}$ to the FlbD::M2 fusion. This entire construction, including promoter and FlbD::M2 fusion, was then ligated into plasmid pRK290/KS1 (Alley et al. 1993), which replicates in Caulobacter.

\section{Overproduction and isolation of FlbD}

Two liters of LB containing $50 \mu \mathrm{g} / \mathrm{ml}$ of ampicillin was inoculated with an overnight culture of $E$. coli TG-1 containing plasmid pTrcHis- $f l b D$. Cells were grown at $37^{\circ} \mathrm{C}$ with vigorous shaking to an $\mathrm{OD}_{600}$ of 0.2 . Isopropylthiogalactoside (IPTG) was added ( $1 \mathrm{~mm}$ final concentration), and growth was continued for an additional $90 \mathrm{~min}$. The cells were harvested by centrifugation for $15 \mathrm{~min}$ at $4300 \mathrm{~g}$ at $4^{\circ} \mathrm{C}$. The pellet was suspended in 100 $\mathrm{ml}$ of TG buffer (10 mM Tris- $\mathrm{HCl}$ at $\mathrm{pH} 7.4,10 \%$ glycerol) and centrifuged again for $15 \mathrm{~min}$ at $12,000 \mathrm{~g}$ at $4^{\circ} \mathrm{C}$. Pellets were resuspended in $30 \mathrm{ml}$ of TG buffer containing $0.1 \mathrm{~mm}$ phenylmethanesulfonyl fluoride and $0.05 \mathrm{~mm} \mathrm{~N}$-tosyl-L-lysine chloromethyl ketone and $N$-tosyl-L-phenylalanine chloromethyl ketone. The cells were lysed in a French pressure cell. Comparison of the soluble protein fraction with the insoluble protein fraction after cell lysis showed that the majority of FlbD was deposited in an insoluble form into inclusion bodies. Inclusion body-containing pellets were obtained by centrifugation of the lysate at $18,500 \mathrm{~g}$ for $30 \mathrm{~min}$ at $4^{\circ} \mathrm{C}$. By SDS-PAGE analysis, FlbD constituted the majority of protein present in the insoluble fraction. The pellets were resuspended in HGEK $10 \mathrm{mM}$ HEPES$\mathrm{HCl}$ at $\mathrm{pH} 7.6,10 \%$ glycerol, $0.1 \mathrm{~mm}$ EDTA, $100 \mathrm{~mm} \mathrm{KCl}$ / containing $6 \mathrm{M}$ guanidine- $\mathrm{HCl}$ and dialyzed stepwise versus 0.5 liters each of nickel-Sepharose loading bufffer $(20 \mathrm{~mm}$ sodium phosphate at $\mathrm{pH} 7.8,500 \mathrm{~mm} \mathrm{NaCl}$ ) containing $2,0.5$, and $0 \mathrm{M}$ guanidine- $\mathrm{HCl}$. All dialysis buffers contained $0.1 \% \mathrm{NP}-40$. The dialysate was centrifuged at $27,000 \mathrm{~g}$ at $4^{\circ} \mathrm{C}$ for $30 \mathrm{~min}$ to remove precipitated protein. The supernatant containing the renatured protein was loaded onto a $2-\mathrm{ml}$ nickel-Sepharose column, which was rinsed with $10 \mathrm{ml}$ of nickel-Sepharose rinse buffer ( $20 \mathrm{~mm}$ sodium phosphate at $\mathrm{pH} 6.0,500 \mathrm{~mm} \mathrm{NaCl}$ ). The protein was eluted with a $20 \mathrm{ml}$ of linear gradient of rinse buffer ending in $300 \mathrm{~mm}$ imidazole, with $0.5 \mathrm{ml}$ fractions being collected. Samples were run on $12 \%$ SDS-PAGE and stained with Coomassie blue. Immunoblot analysis was performed as described by Towbin et al. (1979), using primary antibody (Novagen, Madison, WI) directed against the amino-terminal peptide of the fusion.

\section{DNA-binding assays}

The DNA used in gel mobility shift assays was a doublestranded 40-bp oligonucleotide representing the -120 to -80 region of $f l b G$ (Gober et al. 1991a) that was end-labeled with $\left[\gamma^{32} \mathrm{P}\right]$ ATP (Amersham, Arlington Heights, IL) with T4 polynucleotide kinase. Promoter DNA containing the ftr enhancer el- ements were also used for DNA-binding studies. For $f l b G$, a 120-bp EcoRI-HindIII fragment containing a 112-bp SacI-DdeI fragment of the $f l b G$ promoter, with sequences from -120 to $-8 \mathrm{bp}$ from the transcription start site, was used (Gober et al. $1991 \mathrm{~b}$ ). For $f l g K$, a 319-bp NcoI-EcoRI fragment containing sequences from -150 to +169 -bp from the transcription start was used. A 195-bp BamHI-HindIII fragment (restriction sites introduced by PCR/ contained flgL promoter DNA from -185 to $+10 \mathrm{bp}$. The flaN promoter DNA was a 540-bp EcoRI-PstI fragment from flaN/pUC19 containing a SacI-PstI fragment with sequence from -95 to $+435 \mathrm{bp}$ from the transcription start site. All probes were labeled with $\left[\alpha^{-32} \mathrm{P}\right] \mathrm{dNTPs}$ (Amersham, Arlington Heights, IL) using DNA Polymerase I, Klenow fragment. Gel mobility shift assays were performed as described previously (Gober and Shapiro 1992).

\section{FlbD phosphorylation assay}

Approximately $2.5 \mu \mathrm{g}$ of purified His-FlbD and $5 \mu \mathrm{g}$ of crude protein extract, prepared by sonicating $C$. crescentus NA1000 cells, were added to assay buffer containing $50 \mathrm{mM}$ Tris- $\mathrm{HCl} / \mathrm{pH}$ 7.5), $50 \mathrm{~mm} \mathrm{KCl}, 1 \mathrm{~mm}$ DTT, $0.5 \mathrm{~mm}$ EDTA, and $10 \mathrm{~mm} \mathrm{MgCl}_{2}$. The mixture was warmed for $2 \mathrm{~min}$ at $30^{\circ} \mathrm{C}$, at which time 50 $\mu \mathrm{Ci}$ of $\gamma^{-32} \mathrm{P}$-labeled adenosine triphosphate (Amersham, Arlington Heights, IL) was added. The reaction was stopped by the addition of $50 \mathrm{~mm}$ (final concentration) EDTA. Samples were centrifuged through Sepharose G-25 to remove excess label. SDS-PAGE sample buffer was added, and samples were loaded, without boiling, onto a $12 \%$ SDS-polyacrylamide gel. The gel was dried and exposed to $x$-ray film overnight at $-80^{\circ} \mathrm{C}$. The cell cycle phosphorylation assay was performed identically, with stage-specific extracts prepared from a synchronized culture of NA1000.

\section{Cell cycle expression experiments}

Synchronizable $C$. crescentus NA1000 was grown in M2-glucose medium to an $\mathrm{OD}_{660}=1.0-1.4$. The cells were harvested by centrifugation, and swarmer cells were isolated as by centrifugation in a Ludox gradient (Evinger and Agabian 1977). Pure swarmer cell populations ( $>97 \%$ pure) were suspended in fresh M2-glucose medium and permitted to progress through the cell cycle at $32^{\circ} \mathrm{C}$. At different times thereafter, samples were removed and proteins were labeled for $5 \mathrm{~min}$ with $3 \mu \mathrm{Ci} / \mathrm{ml}$ of Trans ${ }^{35} \mathrm{~S}$-label (ICN, Irvine, CA). Labeled protein was immunoprecipitated as described in Gomes and Shapiro (1984). For cell cycle immunoblots, cells $(1 \mathrm{ml})$ were centrifuged and the pellet was suspended in SDS sample buffer $(0.2 \mathrm{ml})$, boiled and subjected to SDS-PAGE. Immunoblotting was performed as described by Towbin et al. (1979). Monoclonal anti-M2 antibody was obtained from IBI, Inc. (New Haven, CT). Monoclonal anti$\beta$-galactosidase antibody was purchased from Boehringer Mannheim Biochemicals (Indianapolis, IN). Secondary goat antimouse antibody conjugated to alkaline phosphatase was obtained from Bio-Rad (Hercules, CA). Immunofluorescence microscopy was performed on mid-log phase cultures essentially as described by Maddock and Shapiro (1993). Antigenantibody complexes were visualized by the binding of streptavidin Texas Red to biotin-conjugated, goat anti-mouse secondary antibody (GIBCO BRL, Gaithersburg, MD).

\section{DNA manipulations}

Site-directed mutagenesis was performed on Caulobacter DNA in M13 templates grown in $E$. coli strain CJ236 (dut ung) (Kunkel and Roberts 1987). Oligonucleotides for site-directed 
mutagenesis were synthesized on a Pharmacia Gene Assembler automated DNA synthesizer. All site-directed mutagenesis was confirmed by DNA sequencing using the dideoxy chain termination method (Sanger et al. 1977). Plasmids were introduced into Caulobacter by mating with E. coli donor strain $\mathrm{S} 17-1$ (Simon et al. 1983). $\beta$-Galactosidase assays were performed as described previously (Gober and Shapiro 1990).

\section{Acknowledgments}

We thank M.R.K. Alley for providing many plasmid vectors used in this work and J. Maddock for helpful hints on immunofluorescence. E.K.M. is supported by a U.S. Public Health Service predoctoral fellowship (GM-07104). This work was supported by a U.S. Public Health Service grant (GM48417) from the National Institutes of Health and a Junior Faculty Research Award (JFRA-466) from the American Cancer Society to J.W.G.

The publication costs of this article were defrayed in part by payment of page charges. This article must therefore be hereby marked "advertisement" in accordance with 18 USC section 1734 solely to indicate this fact.

\section{References}

Alley, M.R.K., J.R. Maddock, and L. Shapiro. 1992. Polar localization of a bacterial chemoreceptor. Genes \& Dev. 6: 825836.

Alley, M.R.K., J.R. Maddock, and L. Shapiro. 1993. Requirement of the carboxyl terminus of a bacterial chemoreceptor for its targeted proteolysis. Science 259: 1754-1757.

Brun, Y.V. and L. Shapiro. 1992. A temporally controlled $\sigma$-factor is required for polar morphogenesis and normal cell division in Caulobacter. Genes \& Dev. 6: 2395-2408.

Contreras, I., L. Shapiro, and S. Henry. 1978. Membrane phospholipid composition of Caulobacter crescentus. J. Bacteriol. 135: 1130-1136.

Ely, B. and T. Ely. 1989. Use of pulsed field gel electrophoresis and transposon mutagenesis to estimate the minimal number of genes required for motility in Caulobacter crescentus. Genetics 123: 649-654.

Evinger M. and N. Agabian. 1977. Envelope-associated nucleoid from Caulobacter crescentus stalked and swarmer cells. $J$. Bacteriol. 132: 294-301.

Gober, J.W. and L. Shapiro. 1990. Integration host factor (IHF) is required for the activation of developmentally regulated genes in Caulobacter. Genes \& Dev. 4: 1494-1504.

Gober, J.W. and L. Shapiro. 1991. Temporal and spatial regulation of developmentally expressed genes in Caulobacter. BioEssays 13: 277-283.

. 1992. A developmentally regulated Caulobacter flagellar promoter is activated by $3^{\prime}$ enhancer and IHF binding elements. Mol. Biol. Cell. 3: 913-926.

Gober, J.W., M.R.K. Alley, and L. Shapiro. 1991a. Positional information during Caulobacter cell differentiation. Curr. Opin. Genet. Dev. 1: 324-329.

Gober, J.W., H. Xu, A. Dingwall, and L. Shapiro. 1991b. Identification of cis- and trans-elements involved in the timed control of Caulobacter flagellar gene. J. Mol. Biol. 217: 247257.

Gober, J.W., R. Champer, S. Reuter, and L. Shapiro. 1991c. Expression of positional information during cell differentiation in Caulobacter. Cell 64: 381-391.

Gomes, S.L. and L. Shapiro. 1984. Differential expression and position of chemotaxis methylation proteins in Caulobacter crescentus. J. Mol. Biol. 178: 551-568.
Horvitz, H.R. and I. Herskowitz. 1992. Mechanisms of asymmetric cell division: Two Bs or not two Bs, that is the question. Cell 68: 237-255.

Johnson, R.C. and B. Ely. 1977. Generalized transduction in Caulobacter crescentus. Genetics 87: 391-399.

Keener, J. and S. Kustu. 1988. Protein kinase and phophoprotein phosphatase activities of the nitrogen regulatory proteins NTRB and NTRC of enteric bacteria: Roles of the conserved amino-terminal domain of NTRC. Proc. Natl. Acad. Sci. 85: 4976-4980.

Klinger, M., M. Erdelyi, J. Szabad, and C. Nüsslein-Volhard. 1988. Function of torso in determining the terminal anlagen of the Drosophila embryo. Nature 335: 275-277.

Kunkel, T.A. and J.D. Roberts. 1987. Rapid and efficient sitespecific mutagenesis without phenotypic selection. Methods Enzymol. 154: 367-382.

Kustu, S., E. Santero, J. Keener, D. Popham, and D.S. Weiss. 1989. Expression of $\sigma 54(n t r A)$-dependent genes is probably united by a common mechanism. Microbiol. Rev. 53: 367376.

Loewy, Z.G., R.A. Bryan, S.H. Reuter, and L. Shapiro. 1987. Control of synthesis and positioning of a Caulobacter cres. centus flagellar protein. Genes \& Dev. 1: 626-635.

Losick, R. and P. Stragier. 1992. Crisscross regulation of celltype-specific gene expression during development in $B$. subtilis. Nature 355: 601-604.

Maddock, J.R. and L. Shapiro. 1993. Polar localization of the chemoreceptor complex in the Escherichia coli cell. Science 259: $1717-1723$.

Milhausen, M. and N. Agabian. 1983. Caulobacter flagellin mRNA segregates asymmetrically at cell division. Nature 302: 630-632.

Miller, J.H. 1972. Assay of $\beta$-galactosidase. In Experiments in molecular genetics pp. 352-355. Cold Spring Harbor Laboratory, Cold Spring Harbor, New York.

Minnich, S.A. and A. Newton. 1987. Promoter mapping and cell cycle regulation of flagellin gene transcription in Caulobacter crescentus. Proc. Natl. Acad. Sci. 84: 1142-1146.

Mullin, D.A. and A. Newton. 1989. Ntr-like promoters and upstream regulatory sequence $f t r$ are required for transcription of a developmentally regulated Caulobacter crescentus flagellar gene. I. Bacteriol. 171: 3218-3227.

Mullin, D., S. Minnich, S. Chen, and A. Newton. 1987. A set of positively regulated flagellar gene promoters in Caulobacter crescentus with sequence homology to the nif gene promoters of Klebsiella pnenumoniae. J. Mol. Biol. 195: 939-943.

Nathan P., S.L. Gomes, K. Hahenberger, A. Newton, and L. Shapiro. 1986. Differential localization of membrane receptor chemotaxis proteins in the Caulobacter predivisional cell. I. Mol. Biol. 191: 433-440.

Newton, A. and N. Ohta. 1990. Regulation of the cell division cycle and differentiation in bacteria. Annu. Rev. Microbiol. 44: 689-719.

Newton, A., N. Ohta, G. Ramakrishnan, D. Mullin, and G. Raymond. 1989. Genetic switching in the flagellar gene hierarchy of Caulobacter requires negative as well as positive reg. ulation of transcription. Proc. Natl. Acad. Sci. 86: 6651-6655.

Ninfa, A.J. and B. Magasanik. 1986. Covalent modification of the $g \ln G$ product NRI, by the $g \ln L$ product, NRII, regulates transcription of the $\ln A L G$ operon in Escherichia coli. Proc. Natl. Acad. Sci. 83: 5909-5913.

Nixon, B.T., C.W. Ronson, and F.M. Ausubel. 1986. Two-component regulatory systems responsive to environmental stimuli share strongly conserved domains with the nitrogen assimilation regulatory genes $n t r B$ and $n t r C$. Proc. Natl. Acad. Sci. 83: 7850-7854. 
Ohta, N., T. Lane, E.G. Ninfa, J.M. Sommer, and A. Newton. 1992. A histidine protein kinase homologue required for regulation of bacterial cell division and differentiation. Proc. Natl. Acad. Sci.. 89: 10297-10301.

Parkinson, J.S. and E.C. Kofoid. 1992. Communication modules in bacterial signaling proteins. Annu. Rev. Genet. 26: 71112.

Poindexter, J.S. 1964. Biological properties and classifications of the Caulobacter group. Bacteriol. Rev. 28: 231-295.

Popham, D.L., D. Szeto, J. Keener, and S. Kustu. 1989. Function of a bacterial activation protein that binds to transcriptional enhancers. Science 243: 629-635.

Ramakrishnan, G. and A. Newton. 1990. FlbD of Caulobacter crescentus is a homologue of the $\operatorname{Ntr} C\left(\mathrm{NR}_{1}\right)$ protein and activates $\sigma^{54}$-dependent flagellar gene promoters. Proc. Natl. Acad. Sci. 87: 2369-2373.

Reuter, S. and L. Shapiro. 1987. Asymmetric segregation of heatshock proteins upon cell division in Caulobacter crescentus. I. Mol. Biol. 194: 653-662.

Roberts, S.B., N. Segil, and N. Heintz. 1991. Differential phosphorylation of the transcription factor Octl during the cell cycle. Science 253: 1022-1026.

St. Johnston, D. and C. Nüsslein-Volhard. 1992. The origin of pattern and polarity in the Drosophila embryo. Cell 68: 201219.

Sanders, D.A., B.L. Gillece-Castro, A.L. Burlingame, and D.E. Koshland Jr. 1992. Phosphorylation of NtrC, a protein phosphatase whose covalent intermediate activates transcription. J. Bacteriol. 174: 5117-5122.

Sanger, F., S. Nicklen, and A.R. Coulson. 1977. DNA sequencing with chain-terminating inhibitors. Proc. Natl. Acad. Sci. 74: 5463-5467.

Simon, R., U. Priefer, and A. Pühler. 1983. Vector plasmids for in-vivo and in-vitro manipulations of gram-negative bacteria. In Molecular genetics of the bacteria-plant interaction (ed. A. Pühler), pp. 98-106. Springer-Verlag, New York.

Sommer, J.M. and A. Newton. 1991. Pseudoreversion analysis indicates a direct role of cell division genes in polar morphogenesis and differentiation in Caulobacter crescentus. Genetics 129: 623-630.

Sprenger, F., L.M. Stevens, and C. Nüsslein-Volhard. 1989. The Drosophila gene torso encodes a putative receptor kinase. Nature 338: 478-483.

Stock, J.B., M.G. Surette, W.R. McCleary, and A.M. Stock. 1992. Signal transduction in bacterial chemotaxis. J. Biol. Chem. 267: 19753-19756.

Strecker, T.R., J.R. Merriam, and J.A. Lengyel. 1988. Graded requirement for the zygotic terminal gene, tailless, in the brain and tail region of the Drosophila embryo. Development 102: 721-734.

Towbin, H., T. Staehlin, and J. Gordon. 1979. Electrophoretic transfer of proteins from polyacrylamide gels to nitrocellulose sheets: Procedure and some applications. Proc. Natl. Acad. Sci. 76: 4350-4354.

Van Way, S., A. Newton, A. Mullin, and D. Mullin. 1993. Identification of the promoter and negative regulatory element, $f t r 4$ that is needed for cell cycle timing of fliF operon expression in Caulobacter crescentus. J. Bacteriol. 175: 367-376.

Wang, S.P., P.L. Sharma, P.V. Schoenlein, and B. Ely. 1993. A histidine protein kinase is involved in polar organelle development in Caulobacter. Proc. Nat1. Acad. Sci. 90: 630-634.

Weigel, D., G. Jürgens, M. Klinger, and H. Jäckle. 1990. Two gap genes mediate maternal terminal pattern information in Drosophila. Science 248: 495-498.

Weiss, D.S., J. Batut, K.E. Klose, J. Keener, and S. Kustu. 1991. The phosphorylated form of the enhancer-binding protein
NTRC has an ATPase activity that is essential for activation of transcription. Cell 67: 155-167.

Weiss, V. and B. Magasanik. 1988. Phosphorylation of the nitrogen regulator $\left(\mathrm{NR}_{1}\right)$ of Escherichia coli. Proc. Natl. Acad. Sci. 85: 8919-8923.

Xu, H., A. Dingwall, and L. Shapiro. 1989. Negative transcriptional regulation in the Caulobacter flagellar hierarchy. Proc. Natl. Acad. Sci. 86: 6656-6660. 


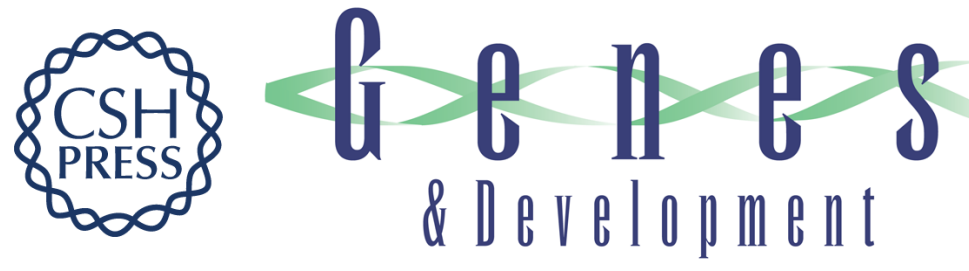

\section{Spatial and temporal phosphorylation of a transcriptional activator regulates pole-specific gene expression in Caulobacter.}

J A Wingrove, E K Mangan and J W Gober

Genes Dev. 1993, 7:

Access the most recent version at doi:10.1101/gad.7.10.1979

References This article cites 52 articles, 33 of which can be accessed free at:

http://genesdev.cshlp.org/content/7/10/1979.full.html\#ref-list-1

License

Email Alerting

Service

Receive free email alerts when new articles cite this article - sign up in the box at the top right corner of the article or click here.

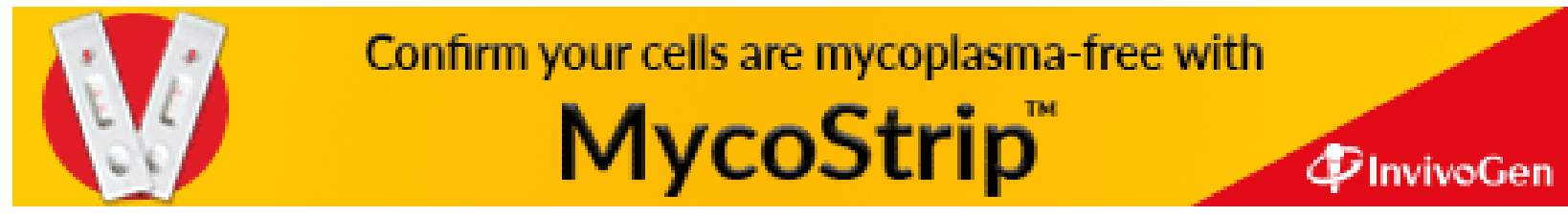

